\title{
Operant drinking behavior and the prediction of instrumental performance
}

\author{
ANDREW LANGFORD, LINDA BENSON, \\ and R. G. WEISMAN, Queen's University at \\ Kingston, Ont, Canada
}

Operant licking probabilities varied as rats were subjected to $6,24,48$, and $72 \mathrm{~h}$ of water deprivation. It was found that instrumental bar-press rates could be predicted successfully at the various deprivation levels from independent operant licking probabilities.

The experiment was designed to test one aspect of a theory of positive reinforcement (Premack, 1959, 1965). Premack's theory distinguished between contingency and noncontingency situations and the rate of responding measured in each of these situations, i.e., the independent and dependent rate, respectively. The noncontingency situation is defined by the absence of a conditional relationship between the presence of a test item and S's responses, while the contingency situation is defined by the presence of such a conditional relationship. Premack's law states that if the responses of an individual are ranked in terms of their independent rates, the higher ranking member of any pair, when made contingent upon the lower ranking member, will reinforce the lower ranking member. A corrollary states that the increment given the lower-rate response is proportional to the independent rate of the contingent or higher-rate response. It follows from these rules that if drinking is made contingent upon bar pressing, then the greater the probability of drinking, the greater the increment in bar pressing. In addition, the rate of the dependent response (bar pressing) should be proportional to, and predictable from, the rate of the independent (licking) response.

\section{METHOD}

Subjects were three adult male LongEvans rats weighing approximately $350 \mathrm{~g}$. Apparatus consisted of an operant conditioning chamber and digital programming and recording modules. Licking was recorded with a modified movement transducer (Griffiths et al, 1967). The conditioning chamber, enclosed in a sound-resistant shell, contained a manipulandum and a retractable drinkometer. An S could gain access to the drinkometer through an aperture in the wall of the chamber.

The procedure consisted of three stages: (1) Following habituation to the conditioning chamber operant-level licking and lever-pressing measures were taken during periods in which $S$ had free access to the water source and manipulandum following $48,6,72$, and $24 \mathrm{~h}$ of water deprivation, in that order. (2) After completion of the operant sessions $\mathrm{S}$ was again allowed to return to normal weight, maintained on a 23.5-h water-deprivation schedule, and then trained to press the lever five times in succession for reinforcement (FR-5). (3) The final stage consisted of recording lever-press responses during sessions when licking was contingent on lever pressing. Records were taken following $24,48,6$, and $72 \mathrm{~h}$ of water deprivation, in that order.

Sessions at each stage were $30 \mathrm{~min}$ in duration, after which $\mathrm{S}$ was returned to the home cage. Sessions were conducted at the same time each day. During Stages 1 and 3,S was allowed a sufficient number of days between each deprivation level to recover normal body weight.

\section{RESULTS AND DISCUSSION}

Operant licking probabilities at each level of deprivation were computed for each rat by dividing the total time (in seconds) spent licking at a rate greater than five licks per second by the total time spent in the experimental chamber (Premack, 1965).

Figure 1 presents the relationship between the number of hours of water deprivation and the operant probability of licking for each $S$. Licking probabilities can be seen to increase as a negatively accelerated function of deprivation time.

Figure 2 shows the number of lever presses during the contingency stage of the experiment as a function of the independent probability of licking determined prior to the establishment of a contingency. For each $S$, the number of lever presses was a linear function of the independent probabil-

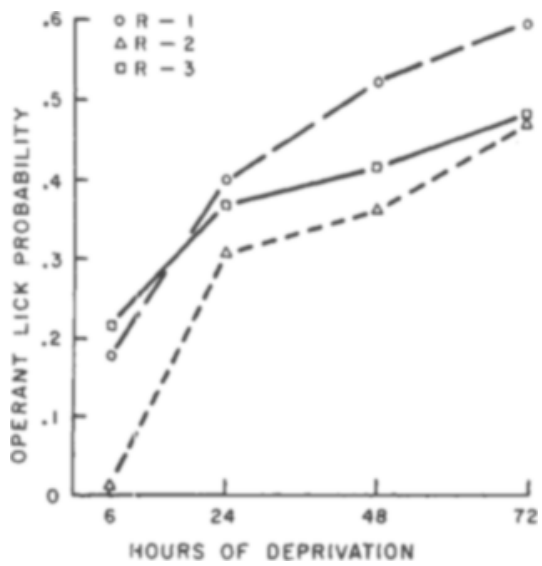

Fig. 1. The independent probability of licking as a function of hours of deprivation.

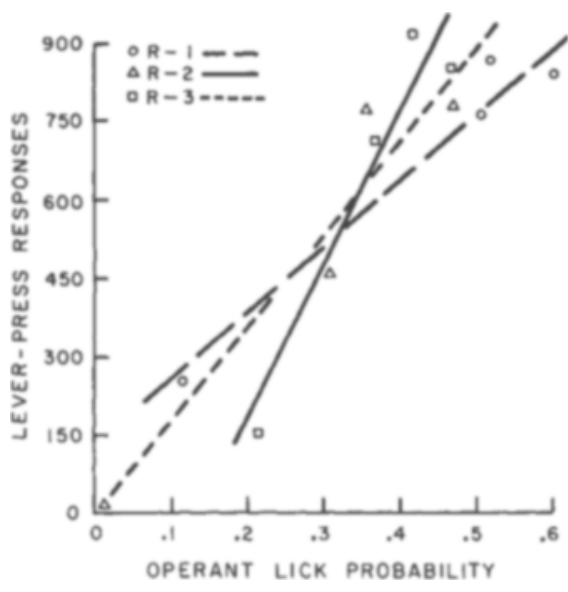

Fig. 2. The number of instrument bar presses as a function of the independent probability of licking.

ity of licking; significant $(\mathrm{p}<.01)$ linearity of regression (Mode, 1965) was observed in each case. Linear regression accounted for an estimated $90 \%$ of the variance in each function. Clearly, the independent probability of the contingent event was a useful and accurate predictor of later operant behavior. Inter-S variability in the slope of the regression line was great. Apparently, increments in the probability of licking resulted in roughly equal increments in bar pressing, but the increment was only "equal" for a given S, not across Ss. Experimental tests of Premack's law using so-called "randomized groups" designs would obviously encounter difficulties because of variability in the reinforcement increment across Ss.

It is interesting that although increasing deprivation did not generate linear increments in the independent probability of licking, changes in independent lick probability produced equal increments in the number of lever presses. One interpretation of this result is that the independent probability of response is the dimension on which we may scale the effects of deprivation, and perhaps most other variables, that affect the rate of later operant behavior (Premack, 1965).

\section{REFERENCES}

GRIFFITHS, E., CHAPMAN, N., \& CAMPBELL, D. An apparatus for detecting and monitoring movement. American Journal of Psychology, $1967,80,438-441$.

MODE, E. B. Elements of statistics. (3rd ed.) Englewood Cliffs, N.J.: Prentice-Hall, 1965.

PREMACK, D. Toward empirical behavior laws: 1. Positive reinforcement. Psychological Review, 1959, 66, 219-233.

PREMACK, D. Reinforcement theory, In Nebraska Symposium on Motivation. Lincoln: University of Nebraska Press, 1965. Pp. 123-180.

\section{NOTE}

1. This research was supported by the National Research Council of Canada (APA-182). 